\title{
ACCOUNTING AND INFORMATION TECHNOLOGY ALIGNMENT: THE INFLUENCE ON ORGANISATIONAL PERFORMANCE
}

\author{
Aderemi Olalere Adebayo \\ Osun State University, Osogbo, Osun State, Nigeria \\ lereadebayo@gmail.com \\ Wasiu Adebayo Lamidi \\ Osun State University, Osogbo, Osun State, Nigeria \\ lamwas4u@gmail.com
}

\begin{abstract}
Alignment of accounting with information technology aims to increase the efficiency and effectiveness of an organisation. This study's main objective is to investigate the influence of accounting with information technology on an organisation's effective performance, such as Cost Reduction, Improving Quality, and Effective Decision Making. Using the population of all Small and Medium Enterprises in Lagos State, Nigeria, 101 valid responses were received from the survey conducted. Based on the analysis results, the study found that accounting and information technology alignment has a positively significant relationship with Cost Reduction and Effective Decision Making. However, accounting and information technology alignment is negatively related to Improve quality. The study then recommends that Small and Medium Enterprises should focus more on investing in the alignment of accounting and information technology to bring about optimum organisation's performance.
\end{abstract}

Keywords: accounting information technology, alignment, cost reduction, improved quality, performance DOI: https://doi.org/10.24818/beman/2021.11.1-03

\section{INTRODUCTION}

Accounting is the engine that tends to make sure an organisation is advancing, and it aids competitors' efforts, agreements of trade, and problems relating to fiscal policies, and so forth. It intends to replicate an organisation's level, financial statements, and results, decision-makers in an organisation gain from these facts once they get hold of it (Legenzova, 2016). For instance, they may determine what path to provide the organisation or what strategies can be developed. Similarly, facts associated with accounting are of utmost importance to the stakeholders of the organisation as an appropriate performance, which can help to decide the gain available to it. The American Institute of Certified Public Accountants partakes in ensuring there are 
standards of information technology (IT) into accounting professionals' knowledge, skills, and competencies (Dillon \& Kruck, 2004). They assert that such capabilities must be applied to organisational performance enhancement efforts. Because of this, organisations must be conscious of the significance of the accounting functions. Else, all the financial information may also turn out to be an underused resource. However, entrepreneurs regularly put up questions related to the IT return on investment, precisely, in the alignment of accounting information technology, even although there are proof of their tremendous impact on a number factors such as productiveness and organisational performance, as they assist in expanding income levels with greater number of clients and enhancing the relationship with them, increase effectivity levels in the enterprise processes, and reduce cost, amongst others (Medina-Quintero et al., 2015).

Alignment of accounting with information technology give birth to accounting information system. Accounting and information system play significant role in the progress of the corporate organisation. The accounting information system of a corporation consists of processes that allow a company to manage past, present, and future accounting information to facilitate the operations of the entity and to aid in taking effective administrative decisions. In addition, it ranges from one individual agency to another and from time to time depending on the user and the purpose of the system. The manager needs to ensure that both the accounting system and the data system are successful. The successful information system could lead the company to excel in achieving its goals. That is, the successful information system means that the business will continue to develop and thrive. On the other hand, the ineffective information system may cause the business to fail to achieve its goals. In this situation, the business may not be able to grow and may die prematurely (Khan, 2017).

Accounting and other information processing is a critical part of financial processes. Yearly, such information in industrialised countries is worth hundreds of millions. There is need study to be carried out to enable management to recognise the implications of concept and process in their organisation, contributing to a more robust decision-making process in a developed country's organisation. The study will be of immense advantage to organizations' executives by providing them with information and insight into accounting and information technology to enhance their decision-making process and customer satisfaction (Alnajjar, 2017). The advancement of IT has contributed to the emergence of modern accounting systems, improved economic models and online business transactions. By helping to increase and enhance interactions and communication for business negotiations, these innovations have minimised time, costs and resources. Through automating current processes to increase the efficiency of operations, an information system is often used by too many organisations to maximise and advance the productivity of business activities. When 
overseeing an organisation and implementing an internal control system, the role of accounting information system is of utmost important (Teru et al., 2017).

A related study by Trabulsi (2018) emphasised the importance of the accounting information system (AIS) as an instrument that can help organisational administration enhance its coordination on the organisation's activities and improve its performance. It also entails identifying, collecting, processing, and providing the record of accounts to employees and decision-makers through all organisation levels. Pérez et al. (2010), in their study, documented that AIS is a system utilised to record the monetary transactions of a business or organisation. This system integrates the strategies, controls, and techniques of accounting to tune financial transactions and supply internal and external reporting facts and support the preparation of financial statements with competencies to enhance organisational performance.

There had been continued use of the paper-based method of reporting, recording, and transacting business; nowadays it seems unsuitable to the changing business system. Revolution in Information systems has changed the idea of big organisations activities and documenting day-to-day transactions, which is driven by the information system and information technology application strategies. The dissemination of such capacities improves overall financial performance. It ensures straightforwardness within the business organisations while presenting relentless access to the financial reports at a specific period of the financial year (Melitski \& Manoharan, 2014).

Besides, in their study, Al-Adaileh (2008) opined that the effective use of information technology and information system applications could enhance the satisfaction of the customer, which may eventually prompt increased augmented performance and efficiency of an organisation. In addition, varying benefits have been attributed to accounting and information technology's alignment such as improved quality, reduction in cost, acceleration in service delivery, well-planned decision, and more effective flow of information. It might likewise give the executives their necessities of important information that are timely, important, evident, and exact to allow them to make the best decision.

Fink (2011) documents that researchers have tended to investigate the strategic value of information technology capabilities. Also, there is sufficient proof of how information technology has been applied in the effectiveness of business undertakings' productivity and in assisting them to have an increasingly competitive advantage in the business world. From that point, this will allow the business organisation to invest their human and economic resources into the production of new products (Medina-Quintero et al., 2015). Accounting and information technology alignment is undoubted of paramount importance nowadays. In the contest of Nigeria, few studies have been carried out on the importance of information technology and its benefits at the organisational level; in this respect, the current study attempt to conduct an empirical investigation on the influence of information technology alignment with accounting among small and 
medium-size enterprises (SME) in Nigeria. Specifically, this study aims to investigate the influence of accounting and information technology alignment on the performance (Cost Reduction, Improve quality, and Effective Decision Making) of SMEs in Nigeria.

Base on the above extant literature, the study intends to answer the following research question:

To what extent does accounting and information technology alignment influence a firm's performance, such as Cost Reduction, improve Quality, and Effective Decision Making of SMEs in Nigeria.

\section{LITERATURE REVIEW}

\subsection{Accounting and Information Technology Alignment}

Information technology alignment may be described as the situation whereby the business system is aligned with the technology strategy. In this view, business strategy assists the organisation in putting together adequate technology for its business process. It is believed that the use of information technology will bring about an increase in performance and lead to an effective and efficient system of managing an organisation. The reason for accounting and information technology alignment is to streamline the worth that information technology adds to the business undertaking. To effectively layout a key information technology guide, it is essential to begin here in that capacity. An enterprise has effectively aligned information technology strategies to business processes when there is the practical understanding of the contribution of information technology to the business either presently or in the future, and when there is mutual knowledge of where to use the limited resources available e.g., specificity of time and money and the competitive challenge the organisation is working towards achieving. When alignment is done, there will be innovation, organisation will have a mutual relationship with information technology organisation and the rest of the organisation's business typified by innovation and speedy operations using technology. Information technology alignment exists when a business association's objectives and exercises are in agreement with the data frameworks that bolster them (Mckeen \& Smith, 2003). The information officers have reliably considered IT alignment with business processes a top need (Watson et al., 1997), and such alignment has been appeared to prompt prevalent business execution (Croteau et al., 2001). Subsequently, any requisites for an organisation's IT ought to be in line with its business system. In this manner, fundamentals investigation hook both an organisation's dynamic business goals and the movements and standards by which those goals are to be achieved (Bleistein et al., 2005).

The importance of information communication technology has positively picked up conspicuousness, given the national aptitude lack in some particular areas, for example, ICT, on the one hand, and the substantial pool of unemployed on the other. ICTs have also picked up conspicuousness regarding the 
abilities they accommodate separation training and enhancing and helping the conventional classroombased instructive procedure. Another area of significance is enhancing productivity and viability in overseeing and directing tertiary establishments. Similarly, as with business enterprise, there is a conviction that IT can add to enhanced hierarchical execution. The alignment of business and IT techniques has been seen as key to acquiring Quality from IT speculations and is, in this way, an imperative range of exploration, given the multi-faceted part for ICT in the training environment. The term alignment used to allude to the necessary business-IT arrangement, while ICT and IT and IS were used reciprocally. It is perceived that these are not synonymous but instead regularly thought to be in an ordinary talk (Motjolopane \& Brown, 2004). Evgeniou (2002) states that there are two determinants of IS/IT strategic planning of business: visibility and flexibility. The organisation's main aim is always to achieve the best performance and make sure the performance is higher than the standard set in terms of quality, productivity, and profitability. Organisation tends to utilise IT to bring innovation or changes to their business, this purpose affects them or determines the organization's decision-making process. Meanwhile, the issue of visibility is another point of note that organisation cares about, they want to achieve a competitive advantage, i.e., be the market leader. To achieve these, many strategic decisions have to be made to help the company achieve. All in all, flexibility and visibility affect the strategic planning process of IT/IS in an organisation (Qiu \& Li, 2009).

Currently, IT's integration with the system of business operations is required progressively in the business environment. This requirement is a result of efficiency and synergy, which is fundamental in an intricate and fierce condition. In other words, this integration would encourage coordination, which is attributed to improving competitive advantage (Granlund \& Malmi, 2002).

\subsection{Empirical Review}

There have been inadequate studies on the relationship between the implementation of accounting and information technology alignment and performance, especially in Nigeria. Focus is on the influence of accounting and information system alignment. Ismail and King (2005) document a positive relationship between accounting and information system alignment and performance of Small and Medium Enterprises. An indirect relationship has also been documented between accounting and information systems and the performance of the firm through varying approaches that may be adopted by organisations (Naranjo-Gil, 2004).

With the investment in accounting and information technology alignment, there has been less visitation to the banking hall by respective customers, which tends to reduce costs that might have been incurred by the customers. Effective use of information technology increases productivity. Since the organisation's 
culture is ready to implement sophisticated accounting information systems, this will bring about a further general assessment of it and provide for better flexibility and dynamism in organisational pursuit for enhanced outcomes. Also, Damanpour and Gopalakrishnan (2001) in their study, documented that companies are opportune to accomplish an extraordinary standard of performance once the organisation can afford the execution of specific technological innovations.

Wah (2000) gathered that after implementing information technology in an organisation, there is a reduction in the company's performance and that it takes several years to realise the benefits of their investment. Many studies have maintained that the company's investment in information technology has not made them flourish in accomplishing the target performance objectives. Even though empirical investigation on the performance of IT is progressively unlimited in big companies, the investigation of the influence on smaller ones results to be exceptionally significant because interest in these innovations may give them a competitive edge and the opportunity to position themselves to achieve an improved outcome, since they are increasingly adaptable and have better response capability (Nabizadeh \& Omrani, 2014). In another study conducted by Muslih et al/ (2020), they documented that information technology governance had a positively significant impact on the performance of state-owned enterprise. The implication of this result is that the use of information technology would contribute to the growth of the company viz a viz the value of the firm. Mohamad et al. (2017) suggest that investment in information technology would produces a significant relationship with all Balanced Scorecard perspectives. Furthermore, Olaofe-Obasesin et al. (2020) investigates the role of accounting information system on organisation performance in Nigeria. Results of the showed that accounting information systems has a positive relationship with the performance of a corporate organizations. The study recommended that having accounting and information system in place would be of utmost importance for the corporate organizations.

With respect to the above extant pieces of literature and findings, the current study proposed the following hypotheses.

H1: Accounting and information technology alignment is positively significant to Cost Reduction, Improve Quality, and Effective Decision and among Small and Medium Enterprises.

\section{METHODOLOGY}

This study employs a quantitative method to conduct this research. The quantitative method paves the way for the collection of data using a questionnaire. It generates numerical data that can after that be 
Adebayo A. 0. \& Lamidi W. A.

ACCOUNTING AND INFORMATION TECHNOLOGY ALIGNMENT: THE INFLUENCE ON ORGANISATIONAL

PERFORMANCE

converted into numbers. A quantitative study can work with a large population, thus making it possible to generalise the study results (Zikmund et al., 2010; Sekaran, 2003). The questionnaire was developed using a 5-point Likert scale. It consists of items on accounting and information technology alignment and the three independent variables of performance, including Cost Reduction, improved quality, and Effective Decision Making (See Appendix).

This study's respondents comprise owners of SMEs (manufacturing and Services) in Lagos, Nigeria. Respondents were selected from each local government area of Lagos State. The study selected Lagos state for it is the central commercial hub in Nigeria. The study used the convenience sampling technique because the population is widely dispersed, while data was collected using a self-administered questionnaire. The sample size selected totalled 120 SMEs owner, while the response rate received was 84.17\% (See Table 1). To examine the relationships between the independent variables and the dependent variable, correlation and multivariate linear regression analyses were done using SPSS software.

TABLE 1. QUESTIONNAIRE ADMINISTRATION

\begin{tabular}{|l|l|l|}
\hline & Total & Percentages \\
\hline Questionnaires Administered & 120 & $100 \%$ \\
\hline Questionnaires Not Received & $(10)$ & $(8.33 \%)$ \\
\hline Response Received & 110 & $91.67 \%$ \\
\hline Invalid Response & $(9)$ & $(7.5 \%)$ \\
\hline Valid Response & 101 & $84.17 \%$ \\
\hline
\end{tabular}

Source: authors

\subsection{The framework of the study}

The study adapted the following model from Trabulsi (2018):

INDEPENDENT VARIABLE DEPENDENT VARIABLES

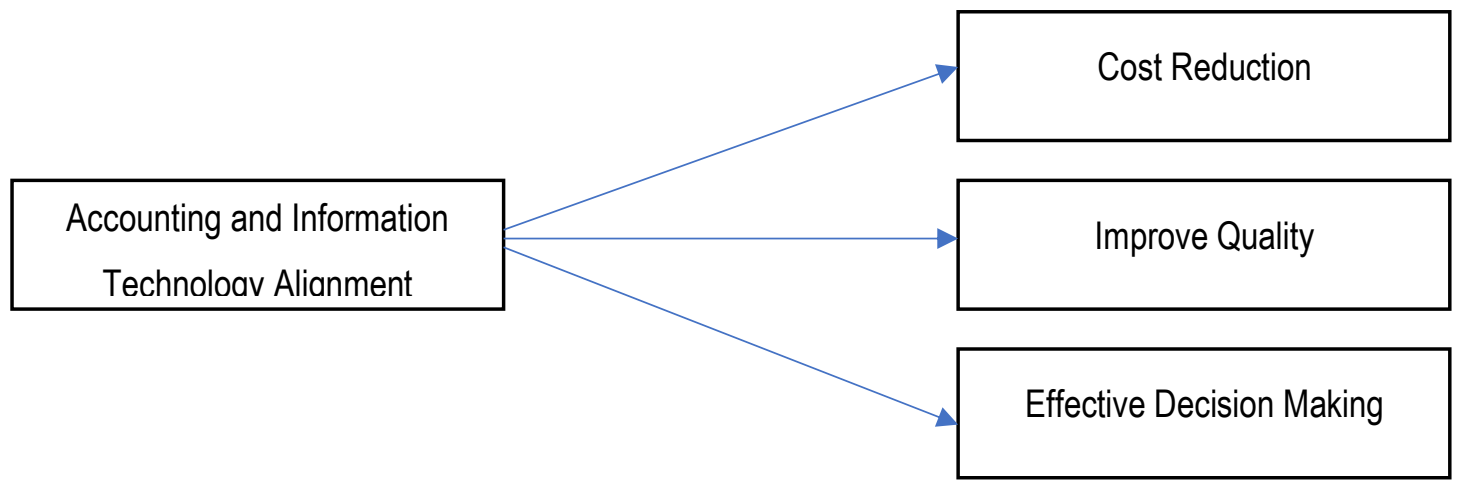

Source: authors based on Trabulsi (2018) 


\section{FINDINGS AND DISCUSSION}

This section discusses the findings and results of the analysis. Table 1 signifies that Cost Reduction has the highest mean and standard deviation value of 4.01 and 0.55 , respectively, followed by Accounting and Information Technology Alignment with a mean of 3.68 and a standard deviation of 0.51 . The third construct, 'improve quality' is attributed to the mean and standard deviation values of 3.41 and 0.49 , respectively. The construct, Effective Decision Making, has a mean of 0.43 . This result indicates that, on average, the respondents agree on all statements related to Cost Reduction, Improve quality, and Effective Decision-Making. They also have a strong perception that the Accounting and Information Technology Alignment would increase the company's performance.

Table 1 also presents the Pearson correlation test conducted. It signifies that Accounting and Information Technology Alignment significantly correlates with Cost Reduction and Effective Decision Making. While non-significant correlation exists between Accounting and Information Technology Alignment and Improve quality, this test enables us to know the direction of the relationship between the study's dependent and independent variables.

Furthermore, the reliability test was presented in Table 1, in behavioural sciences, reliability tests with Cronbach's Alpha not less than .60 are considered enough for the study. Based on these tests' results, it can be concluded that our data are reliable with all the Cronbach's Alpha higher than the standard.

It can also be deduced from Table 2 that variance inflation factor (VIF) for the variables are not beyond the threshold of 10 . These indicate the non-existence of the multicollinearity problem.

TABLE 2. DESCRIPTIVE, RELIABILITY, MULTICOLLINEARITY AND CORRELATION ANALYSIS

\begin{tabular}{lccllllll} 
Construct & Mean & SD & $\begin{array}{l}\text { Cronbach's } \\
\text { Alpha }\end{array}$ & VIF & $\mathbf{1}$ & $\mathbf{2}$ & $\mathbf{3}$ & $\mathbf{4}$ \\
Accounting and Information & 3.68 & .51 & .643 & 1.481 & 1 & & & \\
$\begin{array}{l}\text { Technology Alignment } \\
\text { Cost Reduction }\end{array}$ & 4.01 & .55 & .73 & 1.382 & $.557^{* *}$ & 1 & & \\
Improve Quality & 3.41 & .49 & .72 & 1.133 & .132 & $.453^{* *}$ & 1 & \\
Effective Decision Making & 3.48 & .43 & .85 & 1.259 & $.377^{* *}$ & $.342^{* *}$ & .172 & 1 \\
\hline
\end{tabular}

\section{**. Correlation is significant at the 0.01 level (2-tailed).}

Source: authors

\subsection{Normality Test}

This investigation avails the researcher with an opportunity to depict whether the data under study are normally distributed. According to Munro (2005), normality can be checked by Skewness and Kurtosis and Histogram. George and Mallery (2010) proposed that skewness and kurtosis values between -2 to 
+2 are acceptable to prove normal distribution. Table 2 shows that skewness and kurtosis are within the range of -2 to +2 , signifying that our data are normally distributed.

TABLE 3. NORMALITY TEST

\begin{tabular}{llll}
\hline & Construct & Skewness & Kurtosis \\
\hline 1 & Accounting and Information Technology Alignment & -.134 & -.423 \\
2 & Cost Reduction & -.899 & 1.261 \\
3 & Improve Quality & -.552 & .569 \\
4 & Effective Decision Making & -.783 & 2.240 \\
\hline
\end{tabular}

Source: authors

\subsection{Multivariate Linear Regression}

To investigate the influence of Accounting and Information Technology Alignment on organisation's performance in Nigeria, multivariate linear regression analysis was carried out. Table 5 shows the regression's parameter estimates, which was used to investigate the relationship between variables. Mainly, $\mathrm{H} 1$ was examined, and the results are presented in Table 5 . It can be deduced from Table 5 that Accounting and Information Technology Alignment is positively significant to Cost Reduction. The implication is that the higher the investment in accounting information, the lesser the cost of managing the business operation and vice versa. To reduce the cost incurred in business undertakings such as the cost of information dissemination, ordering process, and efficient recording of the book of account, the information system is of paramount importance. This result is in line with Damanpour and Gopalakrishnan (2001) study, which documents that Accounting and Information Technology Alignment is positively associated with organisation's performance.

Table 5 also indicates a positive non-significant relationship between Accounting and Information Technology Alignment and the variable Improve Quality. The implication non-significant of Accounting and Information Technology Alignment may be that most of the sampled population have not fully aligned their accounting system with information technology, which may arise due to the owner's knowledge of the innovation cost implication in its acquisition. This result is not in line with the study of Wah (2000), which maintained that initial implementation of information technology tends to reduce an organisation's performance and that it takes several years before they realised the benefit of the system.

The result in Table 5 further shows that Accounting and Information Technology Alignment maintained a positively significant relationship with the variable of performance "Effective Decision Making". This is in tandem with Ismail and King (2005) study, which documents that Accounting and Information Technology Alignment has a positive association with a company's performance. The implication is that the more effective the system's implementation, the more efficient the organisation's decision-making. 
Lastly, the study investigated the influence of Accounting and Information Technology Alignment on the performance Score (Cost Reduction, Improve Quality and Effective Decision Making). A positive significant relationship exists between Accounting and Information Technology Alignment and Performance of and organisation. These confirmed that an organization's accounting system with information technology would bring about optimum organisational performance.

TABLE 4. PARAMETER ESTIMATES

\begin{tabular}{llrrrr} 
Dependent Variable & Parameter & \multicolumn{1}{c}{ B } & Std. Error & \multicolumn{1}{l}{ t } & \multicolumn{1}{l}{ Sig. } \\
\hline Cost Reduction & Intercept & 1.939 & .314 & 6.172 & .000 \\
& AlTA & .521 & .078 & 6.669 & .000 \\
Improve Quality & Intercept & 2.938 & .490 & 5.994 & .000 \\
& AlTA & .161 & .122 & 1.323 & .189 \\
Effective Decision Making & Intercept & 2.486 & .418 & 5.942 & .000 \\
& AlTA & .422 & .104 & 4.051 & .000 \\
Performance (Score) & Intercept & 2.454 & .290 & 8.469 & .000 \\
& AITA & .368 & .072 & 5.105 & .000 \\
\hline
\end{tabular}

AlTA denotes Accounting and Information Technology Alignment

Source: authors

\section{CONCLUSION}

This study attempts to construct a more general system of factors that influence the success of the enterprise. The emphasised activities of accounting and information technology may have a significant relationship with organisational cost-effectiveness. It is administrators or supervisors who can determine whether to properly use this information. The advantages of using accounting and information technology are massive.

Accounting is a business language that helps in communicating an organization's performance and helps it face its competitors' efforts, trade agreements, and fiscal issues. The accounting aims to mirror an enterprise's state, financial statements, and outcomes. Decision-makers in a company benefit from this information when they receive it. This study investigates the influence of Accounting and Information Technology Alignment on Small and Medium Enterprises (SMEs) performance in Nigeria. The study found that Accounting and Information Technology Alignment among Small and Medium Enterprises significantly influences Cost Reduction and Effective Decision Making. This implies that what organisation would have spent in the absence of alignment of accounting with information technology would be minimised, and that it will bring about Effective Decision Making. It was also gathered that accounting and 
information technology were negatively influenced. Improve Quality; the implication may be that the alignment of accounting and information technology is still not well utilised among SMEs due to the cost of accusation, availability of resources, and the cost of training.

This study is intended to help foster the interests in aligning accounting and information technology toward an organization's success. It addresses the use of accounting and information technology to achieve greater progress. There is still an inadequate emphasis on the effect of alignment of accounting and information technology on performance. This research could to a certain extend add to the existing knowledge. The findings will also provide an insight for the owners and managers, which allows them to improve their focus in the alignment of accounting and information technology applications as they increase organisational efficiency. Hence, the study recommends that Small and Medium Enterprises (SMEs) consider investing in the use of accounting information systems to bring about the optimum performance of an organisation. Other factors that may influence the use of accounting information systems among SMEs should be considered for further study. The findings of this study cannot be generalised because the scope is limited to SMEs in Lagos, Nigeria.

\section{REFERENCES}

Al-Adaileh, R. (2008). Essentials of Management Information Systems. Karak-Jordan: Yazeed-Publications.

Alnajjar, M. I. (2017). Impact of accounting information system on organisational performance: A study of SMEs in the UAE. Global Review of Accounting and Finance, 8(2), 20-38.

Bleistein, S. J., Cox, K., \& Verner, J. (2005). Strategic Alignment in Requirements Analysis for Organizational IT: an Integrated Approach. ACM Symposium on Applied Computing, (1), 1300-1307. https://doi.org/10.1145/1066677.1066972

Croteau, A. M., Solomon, S., Raymond, L., \& Bergeron, F. (2001). Organisational and technological infrastructures alignment. In System Sciences, 2001. Proceedings of the 34th Annual Hawaii International Conference on (pp. 9). IEEE.

Damanpour, F., \& Gopalakrishnan, S. (2001). The dynamics of the adoption of product and process innovations in organisations. Journal of Management Studies, 38(1), 45-65. http://dx.doi.org/10.1111/1467-6486.00227.

Dillon, T. W., \& Kruck, S. E. (2004). The emergence of accounting information systems programs. Management Accounting Quarterly, 5(3), 29-36.

Evgeniou, T. (2002). Information integration and information strategies for adaptive enterprises. European Management Journal, 20(5), 486-494.

Fink, L. (2011). How do IT capabilities create strategic value? Toward greater integration of insights from reductionistic and holistic approaches. European Journal of Information Systems, 20, 16-33. 
George, D. \& Mallery, P. (2005). SPSS for Windows step by step: A simple guide andreference, 12.0 update. Boston, MA: Pearson Education.

Ismail, N. A., \& King, M. (2005). Firm performance and AIS alignment in Malaysian SME's. International Journal of Accounting Information Systems, 6(4), 241-259. http://dx.doi.org/10.1016/j.accinf.2005.09.001.

Khan, A. (2017). Impact of accounting information system on the organizational performance: a case study of Procter and Gamble. Star Research Journal, 5(12), 26-30.

Legenzova, R. (2016). A concept of accounting quality from accounting harmonisation perspective. Economics and Business, 28(1), 33-37.

McKeen, J. D., \& Smith, H. A. (2003). Making IT happen: Critical issues in managing technology.

Medina-quintero, J. M., Mora, A., \& Abrego, D. (2015). Enterprise technology in support for accounting information systems. An innovation and productivity approach. JISTEM, 12(1), 29-44. https://doi.org/10.4301/S1807-17752015000100002

Melitski, J., \& Manoharan, A. (2014). Strategic information system plans in nations around the world. International Journal of Public Administration, 37(12), 846-855.

Mohamad, A., Zainuddin, Y., Alam, N., \& Kendall, G. (2017). Does decentralized decision making increase company performance through its Information Technology infrastructure investment?. International Journal of Accounting Information Systems, 27, 1-15.

Motjolopane, I., \& Brown, I. (2004). Strategic Business-IT Alignment, and Factors of Influence : A Case Study in a Public Tertiary Education Institution. Integration The VIsi Journal, 147-156.

Munro, B. H. (2005). Statistical methods for health care research (Vol. 1). lippincott williams \& wilkins.

Muslih, M., Rahadi, D. R., \& Sugianti, I. (2020). Sustainable Information Technology Governance to Support the Performance of State-Owned Enterpries. In Proceedings International Seminar on Accounting Society, 2(1), 1-9.

Nabizadeh, S. M., \& Omrani, S. A. (2014). Effective Factors on Accounting Information System Alignment; a Step towards Organisational Performance. International Journal of Scientific and Research, 4(9), 1-5.

Naranjo-Gil, D. (2004). The role of sophisticated accounting system in strategy management. The International Journal of Digital Accounting Research, 4(8), 125-144.

Olaofe-Obasesin, M., Akanni, W. A., Ekundayo, O., Ajibola, O., \& Ajibola, F. (2020). Effects of Accounting Information System on Organization Performance In Nigeria. International Journal of Software Engineering and Computer Systems, 6(2), 69-73. https://doi.org/10.15282/ijsecs.6.2.2020.3.0071

Pérez, E. R., Urquía, G. E., \& Muñoz, C. C. (2010). Information technology implementation: Evidence in Spanish SMEs. International Journal of Accounting and Information Management, 18(1), 39-57.

Qiu, W., \& Li, D. (2009). A Study for End Users' Perceptions of Business Strategic Factors Among Different IS/IT Contexts. ACM SIGMIS Database, 40(1), 52-60. https://doi.org/10.1145/1496930.1496938

Sekaran, U. (2003). Research Method for Business. Journal of Chemical Information and Modeling, 53. https://doi.org/10.1017/CB09781107415324.004

Teru, S. P., Idoku, I., \& Ndeyati, J. T. (2017). A review of the impact of accounting information system for effective internal control on firm performance. Indian Journal of Finance and Banking, 1(2), 52-59. 
Trabulsi, R. U. (2018). The Impact of Accounting Information Systems on Organizational Performance: The Context of Saudi' s SMEs. International Review of Management and Marketing, 8(2), 69-73. Wah, L. (2000). Give ERP a chance. Management Review, 89(3), 20-24.

Watson, R. T., Kelly, G. G., Galliers, R. D., \& Brancheau, J. C. (1997). Key issues in information systems management: an international perspective. Journal of Management Information Systems, 91-115.

Zikmund, W. G., Carr, J. C., Griffi, M., \& Fuller-jacobsen, B. (2010). Business Research Methods. SouthWestern, Cengage Learning, 8(1), 1-18.

\section{APPENDIX}

Items of the Questionnaire Items on Accounting and IT Alignment"

\begin{tabular}{|c|c|}
\hline 1 & $\begin{array}{l}\text { of accounting and information technology contributes positively to the growth of the } \\
\text { on }\end{array}$ \\
\hline 2 & $\begin{array}{l}\text { Whenever accounting and information technology are aligned in an organisation, efficiency will be } \\
\text { enhanced. }\end{array}$ \\
\hline$\checkmark$ & Accounting and IT Alignment contribute to increases turnover in my organisation \\
\hline \multirow[t]{2}{*}{-} & $\begin{array}{l}\text { The accounting and information technology systems helps to reduce errors and frauc } \\
\text { accounting data }\end{array}$ \\
\hline & Items to investigate "Improve quality" \\
\hline 1 & $\begin{array}{l}\text { ormation technology alignmer } \\
\text { es }\end{array}$ \\
\hline 2 & unting a \\
\hline 3 & $\begin{array}{l}\text { The accounting and ir } \\
\text { improved communicat }\end{array}$ \\
\hline \multirow[t]{2}{*}{4} & $\begin{array}{l}\text { The accounting and information technology alignment contribute to im } \\
\text { system of the organisation }\end{array}$ \\
\hline & Items to investigate "Co \\
\hline 1 & The accounting an \\
\hline 2 & tion technology alignme \\
\hline 3 & $\begin{array}{l}\text { Accounting and information technology alignment helps to decrease the total expenses of our } \\
\text { organisation }\end{array}$ \\
\hline \multirow[t]{2}{*}{4} & $\begin{array}{l}\text { Accounting and information technology alignment helps to improve the productivity of our } \\
\text { organisation }\end{array}$ \\
\hline & Items to investigate effectiv \\
\hline 1 & ys fast and quick optimum decisi \\
\hline 2 & ient 0 \\
\hline 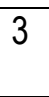 & $\begin{array}{l}\text { Accounting and IT alignment enhances interpersonal interaction (trust, confidence) across in my } \\
\text { organisation }\end{array}$ \\
\hline 4 & The accounting and information technology alignment contribute to the rationalisation and support \\
\hline & \\
\hline
\end{tabular}

